\title{
Relationship between active inflammatory lesions in the spine and sacroiliac joints and new development of chronic lesions on whole-body MRI in early axial spondyloarthritis: results of the ESTHER trial at week 48
}

\author{
I-H Song, ${ }_{1}^{1}$ K G Hermann, ${ }^{2}$ H Haibel, ${ }^{1}$ C E Althoff,, ${ }^{2}$ D Poddubnyy, ${ }^{1} \mathrm{~J}$ Listing, ${ }^{3}$ A Weiß, ${ }^{3}$ \\ B Freundlich, ${ }^{4,5}$ M Rudwaleit, ${ }^{1} \mathrm{~J}$ Sieper ${ }^{1}$
}

- Additional data are published online only. To view these files please visit the journal online at (http://ard.bmj. com).

${ }^{1}$ Rheumatology, Charité Medical University, Campus Benjamin Franklin, Berlin, Germany ${ }^{2}$ Department of Radiology, Charité Medical University, Campus Charité Mitte, Berlin, Germany

${ }^{3}$ Epidemiology Unit, German Rheumatism Research Center, Berlin, Germany

${ }^{4}$ Division of Rheumatology, University of Pennsylvania, Philadelphia, USA

${ }^{5}$ Former Employee, Pfizer/Wyeth Pharmaceuticals, USA

\section{Correspondence to}

Professor J Sieper, Medical Clinic I, Rheumatology, Charité Medical University, Campus Benjamin Franklin, Hindenburgdamm 30, 12200 Berlin, Germany;

joachim.sieper@charite.de

Accepted 13 March 2011 Published Online First 8 May 2011

\section{UNLOCKED}

This paper is freely available online under the BMJ Journals unlocked scheme, see http:// ard.bmj.com/info/unlocked.dtl

\section{ABSTRACT}

Aim To investigate the relationship between active inflammatory lesions on whole-body MRI (wb-MRI) and new development of chronic lesions on $\mathrm{T1} \mathrm{MRI}$ in patients with early axial spondyloarthritis (SpA) treated either with etanercept (ETA) or sulfasalazine (SSZ).

Methods Wb-MRls of 65 patients treated either with ETA $(n=35)$ or SSZ $(n=30)$ over 1 year were scored for active inflammation, fatty lesions, erosions and ankylosis in the 23 vertebral units (VUs) of the spine and in the sacroiliac joints (SI joints). Scoring was performed by two blinded radiologists.

Results If there was no previous inflammation in the bone no new fatty lesions occurred in SI joint quadrants and only a few $(0.6 \%)$ in spine VUs. There was a significant relationship between disappearance of inflammation and the appearance of fatty lesions: if baseline inflammation resolved fatty lesions occurred in $10.5 \%$ of $\mathrm{SI}$ joint quadrants and $17.9 \%$ of VUs. If inflammation did not resolve over 1 year, fatty lesions occurred less frequently: $2.4 \%$ (SI joint quadrants) and $7.2 \%$ (VUs). There was a significantly higher increase of the mean fatty lesion score between baseline and week 48 in the ETA ( 4.0 vs 4.8 for the SI joints and 1.9 vs 2.7 for the spine) compared to the SSZ (3.0 vs 3.2 for the SI joints and 1.1 vs 1.2 for the spine, respectively) group ( $p=0.001$ and $p=0.020$ for the differences). No significant changes in the erosion or ankylosis score were observed in any of the two groups during this time.

Conclusions These data indicate that there is a close interaction between inflammation, tumour necrosis factor blockade and the development of fatty lesions in subchondral bone marrow of patients with axial SpA.

\section{INTRODUCTION}

Treatment of patients with active ankylosing spondylitis (AS) with tumour necrosis factor $\alpha$ (TNF $\alpha$ )blocking agents has been proven to be highly effective for signs and symptoms ${ }^{1-3}$ and also for the suppression of active inflammation of sacroiliac joints (SI joints) and/or spine on MRI. ${ }^{4}$ Against this background, the failure to retard the growth of syndesmophytes as shown on x-rays over a treatment period of 2 years was at first glance a surprise, ${ }^{6-8}$ and has stimulated an intense discussion about the interaction between inflammation and new bone formation in general and especially in the context of AS. ${ }^{9-11}$ Indeed, it has been shown that TNF $\alpha$ blocks the activity of osteoblasts and inhibition of TNF $\alpha$ stimulates osteoblast activity in a TNF transgenic mouse model of arthritis. ${ }^{10} 12$ Thus, it has been postulated that TNF inhibits and TNF blockade stimulates new bone formation. ${ }^{9} 1113$ In several investigations the question was addressed as to whether inflammation is essential for the development of syndesmophytes or whether new bone formation occurs independently from previous inflammation. ${ }^{11} 1415$ Although a correlation between inflammation of vertebral corners at baseline with the growth of syndesmophytes at the same site 2 years later was found in these analyses, new bone formation also occurred at sites with no inflammation at baseline.

Inflammation of subchondral bone marrow (bone marrow oedema) can be demonstrated by the short tau inversion recovery (STIR) sequence of MRI, while chronic changes are seen better or are only visible on MRI T1 sequence. ${ }^{16} 17$ The MRI $\mathrm{T} 1$ sequence is unique among imaging techniques for the detection of fatty lesions of the bone marrow, which is probably the earliest sign of chronic changes as a consequence of inflammation. ${ }^{16}{ }^{17} \mathrm{~A}$ correlation between the presence of active spondylitis on MRI and the subsequent occurrence of fatty lesions at the same sites on MRI T1 has been reported recently in a preliminary study. ${ }^{18}$ Furthermore, a correlation between fatty lesions and the growth of syndesmophytes has been found $^{19}$ indicating that fatty infiltration might be a necessary step between inflammation and new bone formation.

In a recent study we reported a good efficacy of etanercept (ETA) treatment over 1 year in patients with early (symptom duration less than 5 years) axial spondyloarthritis ( $\mathrm{SpA}$ ) on active inflammation of SI joints and the spine as shown by MRI and on clinical parameters, in comparison to treatment over the same period with sulfasalazine (SSZ).${ }^{20}$ In this prospective study patients were randomised to one of the two treatment arms and whole-body MRI (wb-MRI) was read by two scorers blinded for treatment and time points.

In the present study we analysed the development of chronic changes in the bone on T1 MRI such as fatty lesions, erosions and ankylosis over 1 year, the effect of inflammation at baseline on 
the development of chronic lesions and the effect of treatment on the development of chronic lesions in patients from this trial.

\section{METHODS}

\section{Study design}

Patients with axial SpA enrolled in a prospective randomised controlled trial were treated with ETA $(n=40)$ versus SSZ $(n=36)$ over 48 weeks. ${ }^{20}$ All patients showed active inflammatory lesions (bone marrow oedema) on wb-MRI in either the SI joints and/or the spine at baseline (BL). ${ }^{20}$

For this analysis we included the 65 completers (35 patients on ETA and 30 on SSZ) in whom wb-MRI sets at baseline and week 48 were available. Patient characteristics are shown in table 1.

\section{MRI}

Wb-MRIs were performed at weeks 0,24 and 48 on a $1.5 \mathrm{~T}$ scanner (Avanto TIM, Siemens, Erlangen, Germany) according to a previously described protocol. ${ }^{20-22}$ The STIR images were acquired using the following parameters: repetition time (TR) 1660-4590, time to echo (TE) 25-83 and inversion time (TI) 150. The acquired T1 turbo spin-echo (TSE) images comprised a TR of 642-790 and a TE of 10.

$\mathrm{Wb}-\mathrm{MRIs}$ were scored for active inflammation according to a recently described protocol ${ }^{20}$ using the STIR sequences. Chronic changes were scored using the T1 sequences in the 23 vertebral units (VUs) of the spine and the 4 quadrants of each SI joint in case of fatty lesions; erosions and ankylosis were only scored for each SI joint as shown in detail in table 2. Scoring was performed by two radiologists, blinded for treatment arm and MRI time point. T1 and STIR images were scored at the same time.

At baseline, the agreement between both readers (KGH, CA) was high for osteitis and fatty lesions with intraclass correlation coefficients (ICCs) of 0.93 in the spine (SI joints 0.96 ) for osteitis and 0.97 (0.90) for fatty lesions. ICCs were lower for erosions: $0.82(0.80)$ and ankylosis 0.75 (0.96).

\section{Statistics}

Main outcome parameters were changes in chronic lesions (fatty lesions, erosions, ankylosis) assessed by MRI T1 sequence and

Table 1 Baseline characteristics

\begin{tabular}{lccc}
\hline & All & Etanercept & Sulfasalazine \\
\hline Number of patients & 65 & 35 & 30 \\
Age in years, mean (SD) & $33.0(8.5)$ & $33.5(8.7)$ & $32.4(8.4)$ \\
Male, $\mathrm{n}(\%)$ & $39(60.0)$ & $22(62.9)$ & $17(56.7)$ \\
$\begin{array}{l}\text { Symptom duration in years, } \\
\text { mean (SD) }\end{array}$ & $2.7(1.7)$ & $2.5(1.6)$ & $3.0(1.8)$ \\
HLA-B27 positive, $\mathrm{n}(\%)$ & $54(83.1)$ & $30(85.7)$ & $24(80.0)$ \\
$\begin{array}{l}\text { Fulfilled modified New York } \\
\text { criteria, }\end{array}$ & $54(50.8)$ & $17(48.6)$ & $16(53.3)$ \\
Fatty lesions on VU level, $\mathrm{n}(\%)$ & $67(4.5)$ & $49(6.1)$ & $18(2.6)$ \\
Fatty lesions on SI joint quadrant & $202(38.8)$ & $123(43.9)$ & $79(32.9)$ \\
level, $\mathrm{n}(\%)$ & & & \\
Erosions on VU level, $\mathrm{n}(\%)$ & $6(0.4)$ & $4(0.5)$ & $2(0.3)$ \\
Erosions on SI joint level, $\mathrm{n}(\%)$ & $95(73.1)$ & $51(72.9)$ & $44(73.3)$ \\
Ankylosis on VU level, $\mathrm{n}(\%)$ & $10(0.7)$ & $6(0.7)$ & $4(0.6)$ \\
Ankylosis on Sl joint level, $\mathrm{n}(\%)$ & $9(6.9)$ & $7(10.0)$ & $2(3.3)$ \\
\hline
\end{tabular}

Mean values of fatty lesion scores, erosion scores and ankylosis scores shown in table 3.

HLA, human leucocyte antigen; SI joint, sacroiliac joint; VU, vertebral unit. associations between the changes in chronic lesions and changes in active inflammation scores assessed by STIR sequences. To be able to investigate these associations the statistical analysis was restricted to $\mathrm{n}=65$ completers (as described above). The nonparametric analysis of covariance (non-parametric ANCOVA) was used to compare the outcome of the treatment groups by taking the baseline status as covariable into account and the non-parametric Mann-Whitney test was applied to compare treatment groups at baseline. These analyses were based on means of the MRI scores of both readers ( $\mathrm{KGH}, \mathrm{CA}$ ) on the patient level. Missing values at week $24(n=3)$ were replaced by a so-called expectation maximization algorithm (replacement with an individual mean value from baseline and week 48 adjusted for the overall trend). ${ }^{23}$

To evaluate the associations between the changes in chronic lesions and changes in active inflammation scores in a very specific manner these possible associations were investigated in the spine on the VU level and in the SI joints on the level of four quadrants per SI joint in case of fatty lesions and per SI joints for erosions and ankylosis. Regarding changes in osteitis scores, three groups (VUs, or quadrants) were analysed separately; group A: both readers agree on no signs of osteitis in the STIR sequence in this unit at baseline and at week 48, group $\mathrm{B}$ : both readers agree regarding a resolution of inflammation in this unit, group C: units not assigned to A or B but inflammation present at week 48 according to at least one reader (group $\mathrm{C}$ was not further stratified because of insufficient sample size). Regarding the outcome, the development of a new chronic lesion between baseline and week 48, an agreement between both readers was required. Generalised estimation equation (GEE) models with a logit link function were applied to investigate the associations between changes in the MRI scores for fatty lesions and active inflammation. By means of these GEE models groups $\mathrm{A}, \mathrm{B}$ and $\mathrm{C}$ were compared and the percentage of new chronic lesions and their corresponding $95 \% \mathrm{CIs}$ were estimated by taking possible correlations between chronic and active changes in single VUs (or quadrants) within individual

Table 2 Scores for chronic inflammatory changes on MRI

\begin{tabular}{|c|c|c|}
\hline Finding on MRI & Spine score per VU & $\begin{array}{l}\text { SI joint score per } \\
\text { quadrant/joint }\end{array}$ \\
\hline \multirow[t]{4}{*}{ Fatty lesion } & 0: normal bone marrow & $\begin{array}{l}0 \text { : fatty lesions } \\
\text { absent }\end{array}$ \\
\hline & $\begin{array}{l}\text { 1: fatty lesions of }<25 \% \text { of } \mathrm{VU} \\
\text { area }\end{array}$ & 1: fatty lesions present \\
\hline & $\begin{array}{l}\text { 2: fatty lesions of } \geq 25 \% \text { and } \\
<50 \% \text { of } \mathrm{VU} \text { area }\end{array}$ & NA \\
\hline & 3: fatty lesions of $\geq 50 \%$ of VU area & NA \\
\hline \multirow[t]{4}{*}{ Erosions* } & $0:$ no erosion & 0: normal joint margin \\
\hline & $\begin{array}{l}\text { 1: erosion }<25 \% \text { of vertebral end } \\
\text { plate }\end{array}$ & $1: 1-2$ erosions \\
\hline & $\begin{array}{l}\text { 2: erosion } \geq 25 \% \text { of vertebral end } \\
\text { plate }\end{array}$ & 2: $3-5$ erosions \\
\hline & NA & $3:>5$ erosions \\
\hline \multirow[t]{4}{*}{ Ankylosis* } & $0:$ no ankylosis & $0:$ ankylosis absent \\
\hline & $\begin{array}{l}\text { 1: syndesmophyte growth, not } \\
\text { bridging }\end{array}$ & 1: ankylosis present \\
\hline & $\begin{array}{l}\text { 2: syndesmophyte growth, } \\
\text { bridging (anterior/posterior) }\end{array}$ & NA \\
\hline & 3: transdiscal ankylosis & NA \\
\hline
\end{tabular}

Maximum fatty lesion score per patient: 69 for spine and 8 for SI joints; maximum erosion score per patient: 46 for spine and 6 for SI joints; maximum ankylosis score per patient 69 for spine and 2 for $\mathrm{SI}$ joints.

*Erosions and ankylosis in the spine were scored on the VU level; in the SI joints erosions and ankylosis were scored for left and right SI joint (not per quadrant). NA, not applicable; SI joint, sacroiliac joint; VU, vertebral unit. 
patients into account. ${ }^{24}$ SAS software (PROC GLIMMIX; SAS, Cary, North Carolina, USA) was used for calculations. p Values $<0.05$ were considered statistically significant.

\section{RESULTS}

\section{Baseline characteristics}

The inclusion criteria and the patients' characteristics for this trial have been described recently in detail. ${ }^{20}$ Patients' characteristics including chronic MRI lesions at baseline are shown in table 1. In the whole group ( $\mathrm{n}=65)$ fatty lesions were found in $4.5 \%$ of VUs (in $26.2 \%$ of patients) and in $38.8 \%$ of SI joint quadrants (in $69.2 \%$ of patients). Erosions were found in only $0.4 \%$ of VUs but in $73.1 \%$ of SI joints. Ankylosis of VUs occurred in $0.7 \%$ in contrast to $6.9 \%$ of SI joints.

\section{Occurrence of fatty lesions over 1 year in relation to inflammation}

New fatty lesions at week 48 developed in 23 VUs and in $17 \mathrm{SI}$ joint quadrants in all patients. There was a very low rate of new fatty lesions of $<1 \%$ ( $0.6 \%$ for VUs and $0 \%$ for SI joint quadrants) if there was no previous inflammation in the bone (figure $1 \mathrm{~A}$ for spine VUs and figure $1 \mathrm{~B}$ for SI joint quadrants). In the presence of baseline inflammation and disappearance of inflammation at all subsequent time points fatty lesions occurred in $17.9 \%$ (VUs) and $10.5 \%$ (SI joint quadrants), while fatty lesions occurred much less frequently if inflammation was present at week $48: 7.2 \%$ in VUs and $2.4 \%$ in SI joint quadrants (figure 1A,B). Appearance of new fatty lesions in the SI joints and the spine did not correlate with a change in $\mathrm{C}$ reactive protein (SI joints: correlation
(A) $\%$ of
vertebral
units with
new fatty
lesions at
week 48

(B) $\%$ of SI-joint
quadrants
with new fatty
lesions at
week 48

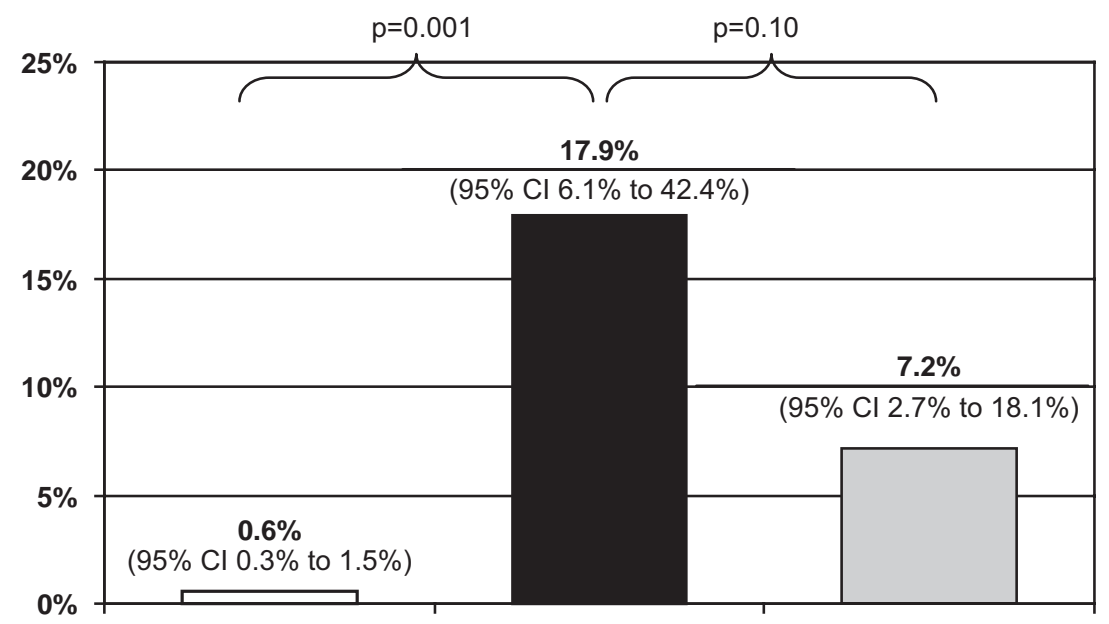

(A) No active inflammation at $\mathrm{BL}$ or at $\mathrm{W} 48$

(B) Active inflammation at $\mathrm{BL}$ and no inflammation at W48

Spine, vertebral units

Figure 1 Frequency of newly developed fatty lesions at the vertebral units of $(A)$ the spine and $(B)$ the sacroiliac joint quadrants at week 48 in relation to active inflammatory lesions. Percentages shown in the three groups in which (A) there was no active inflammation at baseline (BL) and no inflammation at week 48 (W48) vs (B) there was active inflammation at baseline but no inflammation at week 48 (disappearance of active inflammation) vs (C) there was inflammation present at week 48. 
coefficient $=0.018, \mathrm{p}=0.34$; spine: correlation coefficient $=0.055$, $\mathrm{p}=0.95)$.

Fatty lesions present at baseline did not disappear over 48 weeks: 0 out of $67(0 \%)$ at VUs and 2 out of $202(1 \%)$ at SI joint quadrants.

When the change of active inflammation was plotted against the change of the fatty lesion score also on a patient level the correlation between reduction of active inflammation and increase of fatty lesions can be seen (see supplementary figure S1). There was a significant correlation between reduction of active inflammation and increase of fatty lesions in the spine (correlation coefficient $=-0.39, \mathrm{p}=0.001$ ) as well as in the SI joints (correlation coefficient $=-0.76, \mathrm{p}=0.0015$ ).

\section{Occurrence of fatty lesions compared between the two treatment groups}

There was a significantly higher increase of the mean fatty lesion score in the ETA group (4.0 at baseline vs 4.8 at week 48 for the SI joints and 1.9 vs 2.7 for the spine) compared to the SSZ group (3.0 at baseline vs 3.2 at week 48 for the SI joints and 1.1 vs 1.2 for the spine, respectively) ( $p=0.001$ and $p=0.020$ for the differences between the treatment groups) (table 3 ). The increase in the fatty lesion score in the ETA group was already visible after 24 weeks (table 3 ).

The corresponding increase of the fatty lesion score on the patient level is shown in the probability plots in figure 2A (for the spine) and figure $2 \mathrm{~B}$ (for the SI joints). When the nine patients who already had a maximal fatty lesion score of 8 in the SI joints at baseline were excluded from this analysis, the mean baseline values were the same (mean value 2.8) and again the increase in the mean fatty lesion score between baseline and week 48 was significantly ( $p=0.001$ ) higher in the ETA (from 2.8 to 3.9) as compared to the SSZ group (from 2.8 to 3.0).

Figure 3 shows MRI examples without (figure $3 \mathrm{~A}$ ) and with (figure $3 \mathrm{~B}$ ) development of fatty lesions in the spine after suppression of active inflammation.

Table 3 Mean MRI SI joint and spine scores for fatty lesions, erosions and ankylosis at baseline, week 24 and week 48 in patients with axial spondyloarthritis treated with etanercept (ETA) or sulfasalazine (SSZ)

\begin{tabular}{|c|c|c|c|c|c|}
\hline Location & MRI parameter & $\begin{array}{l}\text { Study time } \\
\text { point }\end{array}$ & $\begin{array}{l}\text { ETA } \\
(n=35)\end{array}$ & $\begin{array}{l}\text { SSZ } \\
(n=30)\end{array}$ & p Value* \\
\hline \multirow[t]{9}{*}{ Spine } & Fatty lesion & Baseline $^{\dagger}$ & $1.9(5.0)$ & $1.1(2.6)$ & \\
\hline & \multirow{2}{*}{$\begin{array}{l}\text { score (0-69) } \\
\text { (mean (SD)) }\end{array}$} & Week 24 & $2.6(5.6)$ & $0.9(2.1)$ & 0.033 \\
\hline & & Week 48 & $2.7(5.8)$ & $1.2(2.7)$ & 0.020 \\
\hline & \multirow{3}{*}{$\begin{array}{l}\text { Erosion } \\
\text { score (0-46) } \\
\text { (mean (SD)) }\end{array}$} & Baseline $^{\dagger}$ & $0.2(0.4)$ & $0.3(0.7)$ & \\
\hline & & Week 24 & $0.2(0.4)$ & $0.3(0.8)$ & 0.49 \\
\hline & & Week 48 & $0.2(0.5)$ & $0.3(0.8)$ & 0.21 \\
\hline & \multirow{3}{*}{$\begin{array}{l}\text { Ankylosis } \\
\text { score (0-69) } \\
\text { (mean (SD)) }\end{array}$} & Baseline $^{\dagger}$ & $0.6(2.4)$ & $0.3(1.1)$ & \\
\hline & & Week 24 & $0.6(2.3)$ & $0.2(1.1)$ & 0.10 \\
\hline & & Week 48 & $0.7(2.5)$ & $0.3(1.1)$ & 0.52 \\
\hline \multirow[t]{9}{*}{ SI joints } & \multirow{3}{*}{$\begin{array}{l}\text { Fatty lesion } \\
\text { score }(0-8) \\
\text { (mean (SD)) }\end{array}$} & Baseline $^{\dagger}$ & $4.0(3.2)$ & $3.0(2.8)$ & \\
\hline & & Week 24 & $4.6(3.4)$ & $3.2(2.9)$ & 0.018 \\
\hline & & Week 48 & $4.8(3.2)$ & $3.2(2.9)$ & 0.001 \\
\hline & \multirow{3}{*}{$\begin{array}{l}\text { Erosion } \\
\text { score }(0-6) \\
\text { (mean (SD)) }\end{array}$} & Baseline $^{\dagger}$ & $3.9(2.2)$ & $3.5(2.0)$ & \\
\hline & & Week 24 & $3.8(2.2)$ & $3.6(2.1)$ & 0.060 \\
\hline & & Week 48 & $3.8(2.2)$ & $3.5(2.2)$ & 0.41 \\
\hline & \multirow{3}{*}{$\begin{array}{l}\text { Ankylosis } \\
\text { score (0-2) } \\
\text { (mean (SD)) }\end{array}$} & Baseline $^{\dagger}$ & $0.2(0.6)$ & $0.1(0.4)$ & \\
\hline & & Week 24 & $0.2(0.6)$ & $0.1(0.4)$ & 0.12 \\
\hline & & Week 48 & $0.2(0.6)$ & $0.1(0.4)$ & 0.48 \\
\hline
\end{tabular}

* $p$ Values for comparison of changes in the MRI scores between both groups by analysis of covariance.

${ }^{\dagger}$ No significant differences at baseline between ETA and SSZ: (a) spine: fatty lesions $(p=0.65)$, erosions $(p=1.0)$, ankylosis $(p=0.35)$; (b) SI joints: fatty lesions $(p=0.24)$, erosions $(p=0.346)$, ankylosis $(p=0.50)$.

SI joints, sacroiliac joints.

\section{Development of erosions and ankylosis over 1 year}

As shown in table 3 there was no change in the mean erosion score in the whole group and also no change in the two subgroups (ETA vs SSZ), either in the spine or in the SI joints. The same was true for the mean ankylosis score.

Furthermore, none of the six erosions present in all VUs disappeared $(0 \%)$. Also, there was no change in the ankylosis score in any of the two groups.

\section{DISCUSSION}

In this study we have clearly shown that significant changes of fatty lesions in the SI joints and the spine can be observed over 1 year, but not other changes on T1 MRI: (1) fatty lesions did not occur without previous inflammation in the subchondral bone marrow, (2) the score for fatty lesions increased in patients treated with the TNF blocker ETA but not in patients in the control group treated with SSZ and (3) significant changes in the fatty lesion score could already be seen after 6 months. Finally, (4) no changes in the erosion and ankylosis score were seen over 1 year in any of the two treatment groups. These findings might cast some new light on the interaction between inflammation, chronic bony changes and the development of new bone formation in AS.

Fatty lesions seem to be the first sign of chronic damage in the bone after previous inflammation. This was clearly demonstrated in the current study because fatty lesions occurred only at sites that showed subchondral bone marrow oedema as a sign of active osteitis at baseline, confirming previously reported preliminary results. ${ }^{18}$ Fatty lesions without previous inflammation occurred very rarely. These few cases might be explained by the fact that MRI might have a sensitivity limit in the detection of inflammation, as was shown in a previous study correlating MRI inflammation and histological inflammation. ${ }^{25}$ Interestingly, fatty lesions occurred less frequently if inflammation persisted, indicating that the presence of inflammation might inhibit the occurrence of 'fatty lesions'. However, we cannot exclude a technical problem for this part of the analysis because fatty lesions might not be detectable on an MRI T1 sequence (hyperintense signal) if inflammation is still present (hypointense signal).

The histological correlate of the rather imprecise MRI finding of 'fatty lesions' is not clear at this moment, but probably reflects replacement of subchondral bone marrow by some repair tissue through expansion and/or activation of mesenchymal cells such as adipocytes, fibroblasts and osteoblasts. ${ }^{26} 27$

Fatty lesions at vertebral edges on T1 MRI have also recently been described as early chronic bony changes, which are relatively specific for SpA if they occur at several sites though they do not appear to be different from controls if present only as single lesions in the spine. ${ }^{28} 29$ Thus, although fatty lesions seem to be useful for following up the sequence of events in SpA from inflammation to chronic damage, they are not unique for $\mathrm{SpA}$ unless they show a certain pattern.

The significant increase of fatty lesions in the group of patients treated with ETA over 1 year in comparison to the SSZ-treated group is a very interesting result of the current study. Although such a result seems to be a logical consequence, because ETA was very effective in suppressing active bone inflammation on $M R I$ in the SI joints and the spine in comparison to treatment with SSZ, and active suppression of inflammation was strongly associated with the appearance of fatty lesions, this has not been shown before. Most interestingly, such a (significant) difference between two treatment groups was already visible after 6 months of treatment with a further increase of the difference 

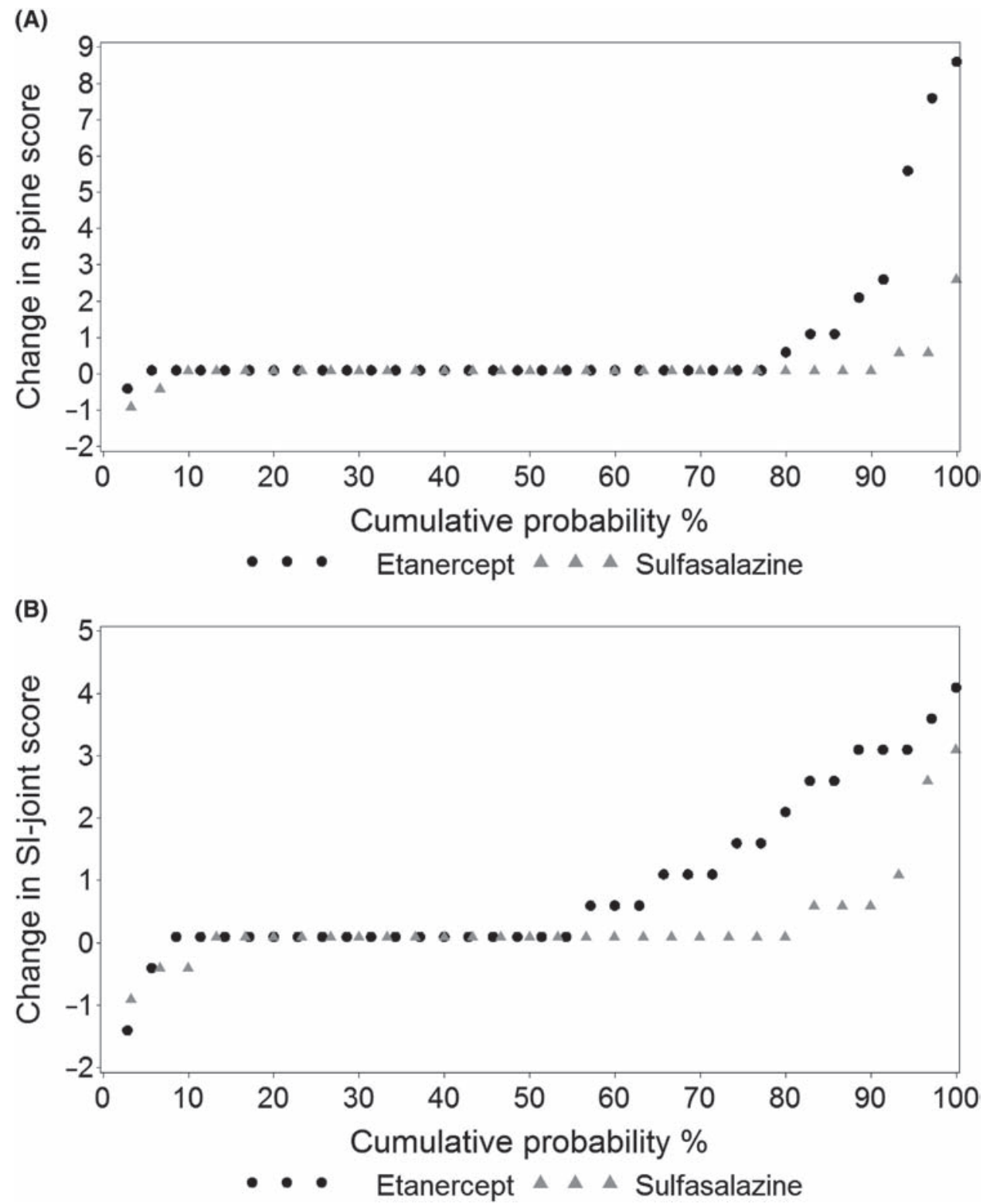

Figure 2 Cumulative probability of changes in MRI fatty lesion scores of $(A)$ the spine and $(B)$ the sacroiliac joints from baseline to week 48 in the etanercept and sulfasalazine treatment groups at the patient level. Each data point in figure $2 A, B$ represents an individual patient.

after 12 months. These data suggest that fatty lesions might prove to be an important early outcome parameter to assess whether suppression of inflammation comes early enough to avoid chronic changes. However, fatty lesions occurred only at about $10 \%$ to $20 \%$ of cleared inflammatory sites, thus in $80 \%$ to $90 \%$ of inflammatory sites inflammation was cleared without the occurrence of fatty lesions. We did not find an improvement of fatty lesions in the spine in any of the treatment groups which is in contrast to results from the already mentioned preliminary study. ${ }^{19}$ However it is difficult to envisage by which mechanism TNF blockade would reverse the presence of fatty lesions.

The key data presented here are further supported by the very similar results obtained for the SI joints and spine, both read blinded to time points. Furthermore, the availability of a control treatment group over 1 year, which was prospectively randomised at baseline, made it possible to compare fatty lesion scores between the two groups.

Beside fatty lesions, erosions and ankylosis are other manifestations of chronic damage in AS. ${ }^{16} 17$ Erosions were observed in $73 \%$ of SI joints but only in $0.4 \%$ of VUs in this early axial SpA group. After 1 year of follow-up, we could neither find a change in erosions nor in ankylosis in either of the two treatment groups. If these patients treated with ETA are followed up longer than 1 year, an improvement of an erosion score might be detectable. ${ }^{19}$ There was a low frequency of ankylosis at baseline, and no change was observed over 1 year. Though MRI is not the method of choice for assessing ankylosis it has been used before for this ${ }^{17} 30$ and for SI joints; ${ }^{16}$ however the role of MRI for the assessment of ankylosis has to be evaluated in future studies.

Long-term outcome in AS is determined by new bone formation (ankylosis) in the spine. Therefore the question arises as to how the occurrence of fatty lesions might be connected to this. We postulate that fatty lesions are the first chronic changes after inflammation and that they are necessary for the later development of syndesmophytes. Thus, if fatty lesions can be avoided this might be an early (in the first 6-12 months) indicator that new bone formation can also be avoided. Indeed, in one investigation radiographic syndesmophytes after 2 years were present in $12 \%$ 
(A)

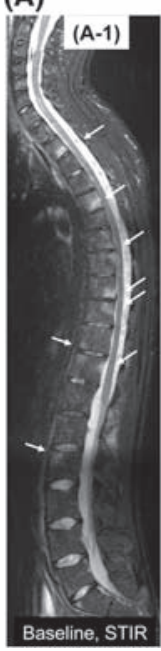

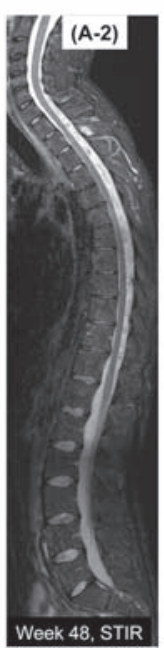
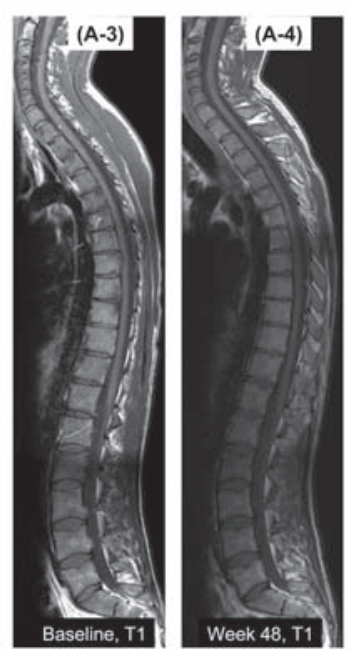

(B)
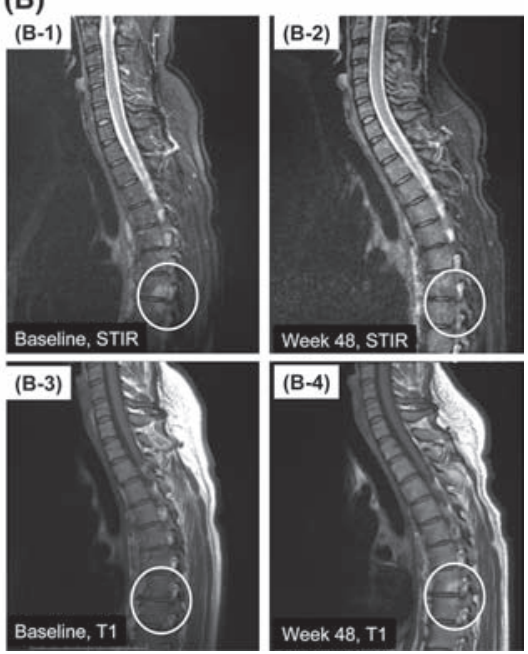

Figure 3 Illustration of spine MRI of two patients treated with etanercept. (A) In patient A active inflammation (as shown by hyperintense signals in short tau inversion recovery sequence) in the spine decreased between (A-1) baseline and (A-2) week 48 but no new fatty lesions developed between (A-3) baseline and (A-4) week 48. (B) Patient B: active inflammatory lesions also decreased between (B-1) baseline and (B-2) week 48 and fatty lesions (as shown by hyperintense sequence in T1 sequence) newly occurred between (B-3) baseline and (B-4) week 48.

of the vertebral edges that showed fatty lesions at baseline but only in $2 \%$ of patients without fatty lesions at baseline, ${ }^{31}$ supporting the proposed link between inflammation, occurrence of fatty lesions and new bone formation. The patients in the current study will be treated long term with ETA and followed up yearly by wb-MRI and by x-rays every 2 years, which will allow this question to be addressed in more detail in the future.

The molecular basis for the link between inflammation and new bone formation in AS is still not clear. It has recently been shown that low serum levels of the molecules sclerostin ${ }^{10}$ and Dickkopf 1 (DKK1), ${ }^{32}$ which are both important for osteoclast activation and osteoblast inhibition, are associated with the formation of new syndesmophytes in patients with AS. Thus, taking all imaging and molecular data in AS together, inhibition and/or low levels of inflammation are necessary for the development of chronic lesions such as fatty lesions in subchondral bone marrow and the development of syndesmophytes. The results reported here on fatty lesions in axial SpA that might provide a missing link between these events.

With regard to TNF blocker treatment of patients with axial SpA, we propose the following scenario: early treatment might prevent the occurrence of early chronic changes such as fatty lesions, which was the case in about $80 \%$ of inflammatory lesions that were successfully cleared by ETA treatment. Whether or not syndesmophytes will develop from these fatty lesions may no longer be dependent on TNF blocker treatment but rather on the genetic background of the patients and on other treatments such as non-steroidal anti-inflammatory drugs, which might have an effect on new bone formation. ${ }^{33-35}$ However, because continuous successful treatment with TNF blockers may avoid or reduce the occurrence of new inflammatory sites ${ }^{20} 36$ new chronic lesions may not occur or their appearance may be reduced, because chronic lesions depend on inflammation initially, as shown in the current study. Thus, a reduction of syndesmophytes growth should be detectable in patients treated long term with TNF blockers. However, because the development of the events discussed is a slow process it may take several years of follow-up to prove this. Future long-term follow-up of patients with AS treated with TNF blockers are necessary to confirm the here-proposed concept.
Funding This study was supported by an unrestricted grant from Wyeth/Pfizer.

Competing interests I-HS: consulting fees or other remuneration from Wyeth/ Pfizer Pharmaceuticals, Merck Sharp Dohme/Schering Plough, Abbott Immunology Pharmaceuticals. KGH: None. HH: consulting fees or other remuneration from Wyeth/ Pfizer, Merck Sharp Dohme/Schering Plough, Abbott Immunology Pharmaceuticals. CA: None. DP: consulting fees or other remuneration from Merck Sharp Dohme/ Schering Plough, Abbott Immunology Pharmaceuticals. JL: None. AW: None. BF: former employee of Pfizer/Wyeth. MR: consulting fees or other remuneration from Wyeth/Pfizer, Merck Sharp Dohme/Schering Plough, Abbott Immunology Pharmaceuticals, UCB. JS: consulting fees or other remuneration from Wyeth/Pfizer, Merck Sharp Dohme/Schering Plough, Abbott Immunology Pharmaceuticals, UCB.

Ethics approval This study was conducted with the approval of the Local ethics committee: Landesamt für Gesundheit und Soziales, Geschaeftsstelle der EthikKommission des Landes Berlin, Saechsische Straße 28, 10707 Berlin, Germany.

Provenance and peer review Not commissioned; externally peer reviewed.

\section{REFERENCES}

1. van der Heijde D, Dijkmans B, Geusens P, et al.; Ankylosing Spondylitis Study for the Evaluation of Recombinant Infliximab Therapy Study Group. Efficacy and safety of infliximab in patients with ankylosing spondylitis: results of a randomized, placebocontrolled trial (ASSERT). Arthritis Rheum 2005:52:582-91.

2. van der Heijde D, Kivitz A, Schiff MH, et al.; ATLAS Study Group. Efficacy and safety of adalimumab in patients with ankylosing spondylitis: results of a multicenter, randomized, double-blind, placebo-controlled trial. Arthritis Rheum 2006:54:2136-46.

3. Davis JC, Jr , Van Der Heijde D, Braun J, et al.; Enbrel Ankylosing Spondylitis Study Group. Recombinant human tumor necrosis factor receptor (etanercept) for treating ankylosing spondylitis: a randomized, controlled trial. Arthritis Rheum 2003;48:3230-6.

4. Braun J, Landewé R, Hermann KG, et al.; ASSERT Study Group. Major reduction in spinal inflammation in patients with ankylosing spondylitis after treatment with infliximab: results of a multicenter, randomized, double-blind, placebo-controlled magnetic resonance imaging study. Arthritis Rheum 2006;54:1646-52.

5. Rudwaleit M, Baraliakos X, Listing J, et al. Magnetic resonance imaging of the spine and the sacroiliac joints in ankylosing spondylitis and undifferentiated spondyloarthritis during treatment with etanercept. Ann Rheum Dis 2005:64:1305-10.

6. van der Heijde D, Landewé R, Einstein $S$, et al. Radiographic progression of ankylosing spondylitis after up to two years of treatment with etanercept. Arthritis Rheum 2008;58:1324-31.

7. van der Heijde D, Landewé R, Baraliakos X, et al.; Ankylosing Spondylitis Study for the Evaluation of Recombinant Infliximab Therapy Study Group. Radiographic findings following two years of infliximab therapy in patients with ankylosing spondylitis. Arthritis Rheum 2008;58:3063-70.

8. van der Heijde D, Salonen D, Weissman BN, et al.; Canadian (M03-606) study group; ATLAS study group. Assessment of radiographic progression in the spines 
of patients with ankylosing spondylitis treated with adalimumab for up to 2 years. Arthritis Res Ther 2009;11:R127.

9. Sieper J, Appel H, Braun J, et al. Critical appraisal of assessment of structural damage in ankylosing spondylitis: implications for treatment outcomes. Arthritis Rheum 2008;58:649-56.

10. Appel H, Ruiz-Heiland G, Listing J, et al. Altered skeletal expression of sclerostin and its link to radiographic progression in ankylosing spondylitis. Arthritis Rheum 2009;60:3257-62.

11. Maksymowych WP, Chiowchanwisawakit P, Clare T, et al. Inflammatory lesions of the spine on magnetic resonance imaging predict the development of new syndesmophytes in ankylosing spondylitis: evidence of a relationship between inflammation and new bone formation. Arthritis Rheum 2009;60:93-102.

12. Diarra D, Stolina M, Polzer K, et al. Dickkopf-1 is a master regulator of joint remodeling. Nat Med 2007:13:156-63.

13. Marzo-Ortega H, Emery P, McGonagle D. The concept of disease modification in spondyloarthropathy. J Rheumatol 2002;29:1583-5.

14. Baraliakos X, Listing J, Rudwaleit M, et al. The relationship between inflammation and new bone formation in patients with ankylosing spondylitis. Arthritis Res Ther 2008; 10:R104

15. van der Heijde D, Landewe R, Baraliakos $X$, et al. Mri-inflammation of the vertebral unit (vu) only marginally contributes to new syndesmophyte formation in that unit: a multi-level analysis. Arthritis Rheum 2008;58(Suppl 9):S905.

16. Rudwaleit M, Jurik AG, Hermann KG, et al. Defining active sacroiliitis on magnetic resonance imaging (MRI) for classification of axial spondyloarthritis: a consensual approach by the ASAS/OMERACT MRI group. Ann Rheum Dis 2009;68:1520-7.

17. Ostergaard M, Maksymowych W, Pedersen SJ, et al. Structural lesions detected by magnetic resonance imaging in the spine of patients with spondyloarthritis definitions, assessment system, and reference image set. J Rheumatol 2009;36(Suppl 84):18-34.

18. Chiowchanwisawakit $\mathbf{P}$, Lambert RG, Maksymowych W. What is the association between inflammation and focal fat infiltration in AS and does treatment matter? Ann Rheum Dis 2010;69(Suppl 3):262.

19. Chiowchanwisawakit P, Lambert RG, Clare T, et al. Fat lesions on MRI predict the development of new syndesmophytes in AS patients receiving standard but not anti-TNF-therapies: evidence for diverse pathways to new bone. Ann Rheum Dis 2010;69:104

20. Song $\mathbf{I H}$, Hermann $\mathrm{K}$, Haibel $\mathrm{H}$, et al. Effects of etanercept versus sulfasalazine in early axial spondyloarthritis on active inflammatory lesions as detected by whole-body MRI (ESTHER): a 48-week randomised controlled trial. Ann Rheum Dis 2011:70:590-6.

21. Mager AK, Althoff CE, Sieper J, et al. Role of whole-body magnetic resonance imaging in diagnosing early spondyloarthritis. Eur J Radiol 2009;71:182-8.
22. Althoff CE, Appel H, Rudwaleit M, et al. Whole-body MRI as a new screening tool for detecting axial and peripheral manifestations of spondyloarthritis. Ann Rheum Dis 2007:66:983-5

23. Molenberghs G, Kenward MG. Missing Data in Clinical Studies. Chichester, UK: Wiley 2007

24. Hardin JW, Hilbe JM. Generalized Estimation Equations. London and New York, NY: Chapman \& Hall 2003.

25. Appel H, Loddenkemper C, Grozdanovic Z, et al. Correlation of histopathological findings and magnetic resonance imaging in the spine of patients with ankylosing spondylitis. Arthritis Res Ther 2006;8:R143.

26. Cruickshank B. Lesions of cartilaginous joints in ankylosing spondylitis. J Pathol Bacteriol 1956; 71:73-84.

27. François RJ, Gardner DL, Degrave EJ, et al. Histopathologic evidence that sacroilitis in ankylosing spondylitis is not merely enthesitis. Arthritis Rheum 2000:43:2011-24.

28. Bennett AN, Rehman A, Hensor EM, et al. The fatty Romanus lesion: a noninflammatory spinal MRI lesion specific for axial spondyloarthropathy. Ann Rheum Dis 2010;69:891-4

29. Kim NR, Choi JY, Hong SH, et al. 'MR corner sign': value for predicting presence of ankylosing spondylitis. AJR Am J Roentgenol 2008;191:124-8.

30. Hermann KG, Althoff CE, Schneider U, et al. Spinal changes in patients with spondyloarthritis: comparison of MR imaging and radiographic appearances. Radiographics 2005;25:559-69.

31. Chiowchanwisawakit P, Lambert RG, Clare T, et al. Post-inflammatory focal fat lesions in the spine of patients with ankylosing spondylitis predict development of new syndesmophytes. Arthritis Rheum 2008:58:356.

32. Sieper J, Appel H, Rudwaleit M, et al. Inverse correlation between serum levels of dickkopf 1 (DKK 1), and new bone formation in ankylosing spondylitis patients. Ann Rheum Dis 2010;69(Suppl 3):442.

33. Wanders A, Heijde D, Landewé R, et al. Nonsteroidal antiinflammatory drugs reduce radiographic progression in patients with ankylosing spondylitis: a randomized clinical trial. Arthritis Rheum 2005;52:1756-65

34. Krischak GD, Augat P, Blakytny R, et al. The non-steroidal anti-inflammatory drug diclofenac reduces appearance of osteoblasts in bone defect healing in rats. Arch Orthop Trauma Surg 2007;127:453-8.

35. Krischak GD, Augat P, Sorg T, et al. Effects of diclofenac on periosteal callus maturation in osteotomy healing in an animal model. Arch Orthop Trauma Surg 2007;127:3-9.

36. Barkham $\mathbf{N}$, Keen $\mathrm{HI}$, Coates $\mathrm{LC}$, et al. Clinical and imaging efficacy of infliximab in HLA-B27-Positive patients with magnetic resonance imaging-determined early sacroilitis. Arthritis Rheum 2009;60:946-54.

37. van der Linden S, Valkenburg HA, Cats A. Evaluation of diagnostic criteria for ankylosing spondylitis. A proposal for modification of the New York criteria. Arthritis Rheum 1984:27:361-8. 